University of Nebraska - Lincoln

DigitalCommons@University of Nebraska - Lincoln

USDA National Wildlife Research Center - Staff Publications
U.S. Department of Agriculture: Animal and Plant Health Inspection Service

January 2005

\title{
Developing relative abundance techniques (RATs) for monitoring rodent populations
}

Desely A. Whisson

University of California

Richard M. Engeman

USDA-APHIS-Wildlife Services, s_r100@yahoo.com

Kellie Collins

University of California

Follow this and additional works at: https://digitalcommons.unl.edu/icwdm_usdanwrc

Part of the Environmental Sciences Commons

Whisson, Desely A.; Engeman, Richard M.; and Collins, Kellie, "Developing relative abundance techniques (RATs) for monitoring rodent populations" (2005). USDA National Wildlife Research Center - Staff Publications. 44.

https://digitalcommons.unl.edu/icwdm_usdanwrc/44

This Article is brought to you for free and open access by the U.S. Department of Agriculture: Animal and Plant Health Inspection Service at DigitalCommons@University of Nebraska - Lincoln. It has been accepted for inclusion in USDA National Wildlife Research Center - Staff Publications by an authorized administrator of DigitalCommons@University of Nebraska - Lincoln. 


\title{
Developing relative abundance techniques (RATs) for monitoring rodent populations
}

\author{
Desley A. Whisson ${ }^{\mathrm{A}}$, Richard M. Engeman ${ }^{\mathrm{B}}$ and Kellie Collins ${ }^{\mathrm{A}}$ \\ ADepartment of Wildlife, Fish and Conservation Biology, University of California, \\ One Shields Avenue, Davis, CA 95616, USA. \\ BUSDA-APHIS National Wildlife Research Center, 4101 La Porte Avenue, Fort Collins, CO 80521-2154, USA.
}

\begin{abstract}
Accurate density estimates of rodents are frequently difficult or cost-prohibitive to determine. Thus, a number of techniques (track plates, monitoring blocks, chew cards/sticks, apple slice index, trapping) are often used to index rodent populations. Theoretically, the sensitivity of these indexing techniques could be improved if they applied continuous measurements rather than simple binary measurements (presence/absence). Development of a relative abundance technique that is simple to apply and sensitive to changes in population density is critical for the operational management of rodent pests. In addition to providing a quantitative measure of abundance with statistical parameters, an indexing technique that does not require handling of animals is important in consideration of potential disease issues (for example, hantavirus, arenavirus, etc.). We investigated track plates, chew cards and monitoring blocks and associated continuous measurement methods for calculating indices of rodent abundance. In laboratory and field settings, we tested their effectiveness in detecting different population densities of California meadow voles (Microtus californicus). Chew cards were poorly accepted by meadow voles in pen and field tests. However, track plates and monitoring blocks may provide useful tools for indexing meadow vole populations, and have application for other rodent species.
\end{abstract}

\section{Introduction}

Monitoring changes in animal abundance over time is an important component of an integrated pest-management program, assisting in determining when and where control should be applied as well as determining the efficacy of the control program (Engeman and Witmer 2000). However, it is frequently difficult and cost prohibitive to assess accurately the density of the population of interest. Furthermore, the assumptions on which traditional density estimators (e.g. mark-recapture) are based are frequently violated, resulting in estimates of questionable quality. In many situations, an index that tracks population changes may be sufficient in providing the necessary information to make management decisions or to evaluate the impact of a control program (Caughley 1977). To be practical, such an index should be simple and easily applied in the field while being sensitive to population changes. Compared to density estimators, indexing methods are usually easier to employ, cost less, and reduce the risk of contact with the animal (Engeman and Witmer 2000).

Development of simple, quantitative, indexing techniques is important for managing a variety of rodent pests in urban, agricultural, and natural resource situations. In addition to providing a quantitative assessment of abundance, an indexing technique that does not require handling of animals is especially important with respect to potential disease issues (hantavirus, arenavirus, etc.). Meadow voles (Microtus californicus and $M$. montanus) are just one of the major pests for which reliable indexing methods are needed. They are frequently the cause of significant economic losses in a variety of field, row and orchard crops in North America (Johnson and Johnson 1982; O'Brien 1994). The relatively small size of meadow voles and the dense vegetation of their preferred habitats may hinder their detection during periods of low population levels. However, considering the high reproductive potential of meadow voles, it is during this period that monitoring is essential to determine the location of populations and to track changes in abundance. An effective indexing technique could provide information to help time control programs as well as assess the effectiveness of control programs. Currently, indexing for meadow voles usually relies on consumption of apple slices (Byers 1975; Hayes and Cullinan 1984; Tobin et al. 1992), or use of snap traps (Department of Pesticide Regulation 2002). These index methods provide binary measurements only, so do not provide the sensitivity required for an effective index. In addition to the potential for operator bias in setting traps, trapping is undesirable owing to possible health risks associated with handling meadow voles or non-target captures (e.g. deer mice that may carry hantavirus).

Indices based on counts of rodent sign (e.g. Tobin et al. 1992), visual counts of active animals (e.g. Engeman and 
Whisson 2003), trapping results (e.g. Redpath et al. 1995), consumption of bait (e.g. Taylor and Thomas 1993), visits to track plate or scent stations (e.g. Mabee 1998), and remote camera results (Cutler and Swann 1999), have been developed and used to index rodent populations in a variety of urban, agricultural, and natural resource situations. Of these methods, trackplates, monitoring blocks, and chew cards probably have the widest application to indexing a variety of rodent pests. They satisfy the desirable properties of an indexing method (Engeman and Witmer 2000), in that they are inexpensive to apply, have minimal observer bias, are robust to the environment, and are potentially sensitive to population change. In addition, continuous measurements may be taken, allowing estimation of statistical parameters similar to those derived for passive tracking plots (Allen et al. 1996; Engeman et al. 1998).

Track plates are often favoured over trapping as being less time-consuming, less expensive and having reduced risks associated with animal contact, while still providing a reliable estimate of the population (Drennan et al. 1998). The percentage of track plates visited may be used to provide an index of abundance (e.g. Drennan et al. 1998); however, track plates are more frequently used simply to determine the presence of a species in an area or habitat type. Various types of baited and unbaited track plates have been used depending on the species and environmental conditions. For example, Mabee (1998) developed a weather-resistant tracking tube for indexing populations of mice and rats in New Zealand. The tube is made from a $30-\mathrm{cm}$ section of $5-\mathrm{cm}$-diameter PVC pipe. Inked squares are placed at either end of the tube and a sheet of paper between them. An animal entering the tube stands on the ink and leaves a positive track on the paper. Other track plates are dusted with chalk or smoked so that an animal standing on the plate leaves a negative track.

Chew cards (or bait cards) were developed for monitoring house mouse (Mus domesticus) populations in graingrowing regions of Australia (Caughley et al. 1998). The cards were $10 \mathrm{~cm} \times 10 \mathrm{~cm}$ squares of paper, divided into $1-\mathrm{cm}^{2}$ grid cells, and soaked in canola oil. Cards were placed in lines of 10 cards at 10-m spacing in mouse habitats. The number of $1-\mathrm{cm}^{2}$ grid cells remaining after the indexing period was used to estimate the percentage of card eaten. Caughley et al. (1998) found a significant positive relationship between the mean percentage of cards chewed and trap success, except when mouse populations were extremely high or low.

There are few reports of using non-toxic bait consumption as an index of rodent populations, although consumption of toxic bait has often been used to index rodent population declines during baiting programs (Cruz and Cruz 1987; Taylor and Thomas 1993). A number of commercial formulations of non-toxic monitoring blocks are available (e.g. Detex Blox®, Bell Labs, Inc.), but marketed mainly for use in structural pest-control applications. These blocks are the non-toxic versions of baits and are used to detect rodent populations and to determine the potential acceptance of the toxic bait.

The objective of our study was to evaluate track plates, chew cards, monitoring blocks, and associated continuousmeasurement methods for calculating indices of rodent abundance. In laboratory, outdoor pen, and field trials we evaluated these methods and their statistical parameters for measuring the relative abundance of meadow voles (M. californicus).

\section{Methods}

We tested acceptance of chew cards and monitoring blocks by individually caged voles, and small groups (one, two or four animals) of voles in the laboratory. We also tested these techniques, and track plates in outdoor pens containing populations of 4,16 or 32 voles; and in four field sites of unknown population size.

All meadow voles used in laboratory and pen tests were collected in artichoke fields in Castroville, California, and maintained in covered outdoor peas ( $3 \mathrm{~m} \times 4.5 \mathrm{~m}$ ), at the Vertebrate Pest Ecology Laboratory, University of California, Davis (UCD), until needed for testing. They were provided with hay bales and wooden shelter boxes for nesting, and food (Purina laboratory chow and artichokes) and water ad libitum. Test methods were approved by UCD Animal Use and Care Administrative Advisory Committee (Protocol 10095).

\section{Chew cards}

We chose $7.5-\times 12.5-\mathrm{cm}$ Oxford blank index cards because they are inexpensive, easy to obtain, a constant size, and relatively durable. We tested untreated cards, and cards brushed with an attractant. Cands were allowed to dry prior to placing them in a test. Five attractants (apple juice, canola oil, artichoke juice, peanut oil, and V8 juice) were tested. Artichoke juice was made by blending fresh artichokes and extracting the juice. We measured the proportion of a card chewed after $24 \mathrm{~h}$, by scanning the chewed cand on a black background with an HP Scanjet $3500 \mathrm{C}$ at $1200 \mathrm{dpi}$ in black and white format, and determining the area remaining as the number of white pixels in Corel Photo Paint ver. 11.633 (Corel Corporation). This was subtracted from the mean number of pixels from 5 unused cards to determine the proportion chewed.

\section{Monitoring blocks}

We made $50-\mathrm{g}$ monitoring blocks by mixing equal proportions of melted paraffin and steam-rolled oats and allowing it to set in $300-\mathrm{mL}$ paper cups. This formulation was selected over commercially available (non-toxic) bait blocks, because of its high acceptance by rodents in laboratory tests (Salmon et al. 2002).

\section{Track plates}

Track plates were $15-\times 20-\mathrm{cm}$ pieces of white vinyl flooring painted with a 1:4 mixture of blue chalk powder and $95 \%$ ethanol solution. We painted plates as evenly as possible with an $8-\mathrm{cm}$-wide sponge brush and allowed them to dry. Rodents stepping on the plate leave a negative track. The number of tracks per plate and the area of the track plate tracked away were estimated for each 24 h test period. To determine the area tracked, we scanned plates on a dark background (pen tests), or took a digital photo of plates (field tests), and counted the number of white pixels (i.e. area with tracks), using the same method as for chew cards.

\section{Laboratory tests}

Ten adult meadow voles were individually housed in suspended wire cages $(20 \mathrm{~cm} \times 20 \mathrm{~cm} \times 20 \mathrm{~cm})$ in the animal room of the Vertebrate Ecology Laboratory, UCD. Each vole was provided with a small nest 
chamber, laboratory chow, and water ad libitum. We allowed a oneweek acclimation period prior to testing. For initial screening of attractants, we reconded the percentage of a cand chewed by each vole over two days. Each vole was tested with each attractant (V8 juice, artichoke juice, apple juice, canola oil, and peanut oil). The testing order of attractants was randomised.

We selected canola oil as the most promising attractant because of its high acceptance in the initial screening tests. Because cards soaked in oil repelled water, we considered that an oil based repellent may also be more durable in the field. We tested canola oil chew cards with 20 individually caged voles, measuring the percentage chewed each day for four days. Fresh cands were provided daily. After three days, we then tested monitoring blocks with these voles. For each test, consumption (in grams) of monitoring blocks was measured each day, for two days.

We tested acceptance of chew cands (canola oil attractant) and monitoring blocks by one, two or four voles housed in plastic containers $(72 \mathrm{~cm} \times 48 \mathrm{~cm} \times 40 \mathrm{~cm})$. There were four containers of each of these vole population densities. We provided the voles with bedding material (Care Fresh), nesting chambers, and laboratory chow and water ad libitum. We allowed a three-day acclimation period to the testing containers prior to testing.

\section{Pen tests}

Outdoor pens were $5.5 \times 4.5 \mathrm{~m}$ wide and $2 \mathrm{~m}$ high, and enclosed with 1.25 -cm woven wire mesh. Stainless steel mesh was buried to $30 \mathrm{~cm}$ under the pens. Grass and weeds covered approximately one-hatf of each pen. We scattered straw over bare areas to provide voles with additional cover. We provided voles with water in poultry feeders, and lab chow in a covered feeding station ad libitum, placed randomly in each pen. We placed 4, 16 or 32 meadow voles per pen, with two pens of each density (six pens total). We allowed a three-day acclimation period to the pens prior to testing. For each group of voles, we sequentially tested chew cards and monitoring blocks, and repeated this twice. Track plates were tested simultaneously with other tochniques. Tests were four days long with three days between tests. Index measurements were reconded daily. For each test, we placed four index stations per pen. The location of these was changed between tests to ensure that voles were not being conditioned to visit particular locations.

\section{Field tests}

We established four $20 \mathrm{~m} \times 20 \mathrm{~m}$ sites in an unmanaged grassland aree on the UCD campus. Sites were separated by at least $20 \mathrm{~m}$. Within each site, we established 16 index stations on a $4 \times 4$ grid, with $4 \mathrm{~m}$ between stations. For four days per site, we simultaneously tested chew cands, and monitoring blocks at each station. These indexing media were placed at least $50 \mathrm{~cm}$ apart. We randomly placed four track plates within each site, and without regard to the location of the 16 index stations. For six days after testing, we live-trapped, marked, and released voles in each site to obtain estimates of the number of voles known to be alive in each site. We placed two live traps (Sherman) baited with a mixture of oats and peanut butter at each index station. Traps were set at dusk and checked and closed the following morning. We marked voles by clipping a small piece from an ear.

\section{Data analysis}

We used an analysis of variance (SAS PROC GLM: SAS Institute 1996) to test the effect of attractants on acceptance of chew cards. For each index method test, we calculated a general index (GI) and associated variance (Engeman et al. 1998) for the continuous measures of (1) the proportion chewed from a chew card (2) the amount (in grams) of monitoring block consumed, (3) the number of tracks on a tracking plate, or (4) the area of tracks (in pixels) on a tracking plate; also, where possible, the corresponding binary measures (chewed/not chewed or tracked/not tracked) of these index methods were determined. With this analysis, a linear model incorporating random effects (e.g. McLean et al. 1991; Wolfinger et al. 1991) was used to describe the measurement at each station each day, and no assumption of independence among stations or days was made:

$$
\mathbf{x}_{i j}=\mu+\mathrm{S}_{i}+\mathrm{D}_{j}+\mathrm{e}_{i j}
$$

where the term $\mu$ is the overall mean measurement value per station per day for the area being assessed. $D_{j}$ is a random effect due to the day on which an observation was made, with $j=1,2,3 \ldots d . S_{i}$ is a random effect due to the $i$ th station with $i=1,2,3 \ldots s \leq s$ representing the number of stations contributing data on the $j$ th day. The $e_{i j}$ represents random observational noise, and is considered independent and identically distributed with mean $=0$ and variance $=\sigma_{c}{ }^{2}$.

The GI is the mean of the daily means, and can be written in the previously defined linear model terminology as:

$$
\mathrm{GI}=\frac{1}{d} \sum_{j=1}^{d} \frac{1}{s_{j}} \sum_{i=1}^{s_{j}} x_{i j}
$$

We used variance component analysis (Searle et al. 1992) to identify whether observation station or day contributed most to the variability among observations for each index. Analyses were conducted with SAS PROC VARCOMP (SAS Institute 1996), using a restricted maximum-likelihood estimation procedure (REML):

$$
\operatorname{var}(\mathrm{GI})=\frac{\sigma_{s}^{2}}{d} \sum_{j=1}^{d} \frac{1}{s_{j}}+\frac{\sigma_{d}^{2}}{d}+\frac{\sigma_{e}^{2}}{d^{2}} \sum_{j=1}^{d} \frac{1}{s_{j}}
$$

where the $\sigma_{\mathrm{s}}{ }^{2}, \sigma_{\mathrm{d}}{ }^{2}$ and $\sigma_{\mathrm{c}}{ }^{2}$ are, respectively, the variance components for station, day, and random observation, associated with each station each day.

We used correlation analyses to examine the relationship between the GI for each monitoring technique with vole population density in each test.

\section{Results}

\section{Chew card attractants}

The proportion of cards chewed varied significantly with attractant type $\left(F_{5,54}=3.03, P=0.018\right)$ (Table 1$)$. Canola oil was the best attractant, with a mean of 0.65 of the card chewed after two days.

\section{Chew cards (with canola oil) and monitoring blocks}

For individually caged voles, chew cards were not chewed for $37.5 \%$ of observations, and completely chewed for $40 \%$ of observations. The variance component for station (20 stations each comprising one caged animal) exceeded that for observation days (four days). The GI was 0.482 for continuous data, and $\mathbf{0 . 6 2 5}$ for binary data. Monitoring blocks had no consumption recorded for only $5 \%$ of observations, and blocks were never completely consumed. As with the chew cards, the variance component for station was much higher than for day. The Gl was $\mathbf{0 . 1 2 2}$ for continuous data and 0.900 for binary data.

For groups of one, two or four voles, each container was considered as an observation station for its population density. The variance component for station was higher than for day for chew cards. The GI values for proportion of cards chewed and proportion of monitoring block consumed were highly correlated with population density (Table 2 ). 
Table 1. The mean proportion of cards chewed by meadow voles after two days, for five different attractants, and an untreated chew card

\begin{tabular}{lc}
\hline Attractant & Proportion chewed \\
\hline Canola oil & 0.65 \\
V-8 & 0.52 \\
Apple juice & 0.49 \\
Artichoke juice & 0.49 \\
Untreated & 0.44 \\
Peanut oil & 0.02 \\
\hline
\end{tabular}

\section{Pen tests}

Chew cards were poorly accepted in pen tests. Of 320 cards used in the testing, $307(96 \%)$ cards were not chewed at all. Monitoring blocks were more frequently eaten. Of 224 blocks, 30 (13\%) were completely consumed, 51 (23\%) were $11-99 \%$ consumed, $44(20 \%)$ were $1-10 \%$ consumed, and $99(44 \%)$ were untouched. We recorded tracks on 358 track plates $(97 \%)$. The number of tracks and pixels tracked were highly correlated $\left(r_{\mathrm{p}}=0.91\right)$. Some data for track plates were lost due to rain during the test period.

None of the indices were significantly correlated with vole population density (Table 3 ). Although GI values increased for a population increase from 4 to 16 voles, they were similar for populations of 16 and 32 voles. Because almost all track plates were tracked regardless of population density, we did not include binary measurements for this method.

\section{Field tests}

Consumption of chew cards was so low that chew card data could be considered only as a binary measurement (Table 4). Only the monitoring blocks and tracking tiles were suitable

Table 2. The general index (GI) values for chew cards and monitoring blocks, for laboratory populations of one, two and four meadow voles, and their correlation with population density

\begin{tabular}{lcc}
\hline Vole density & Chew card GI & Monitoring block GI \\
\hline 1 & 0.1900 & 0.072 \\
2 & 0.1456 & 0.112 \\
4 & 0.3031 & 0.320 \\
$r_{\mathrm{p}}$ & 0.82 & 0.98 \\
\hline
\end{tabular}

for the GI calculations using a continuous measurement. Data for track plates were lost for two sites owing to rain. Meadow voles represented $98 \%$ of captures for all sites, with incidental captures of house mice (Mus musculus).

The GI values for chew cards were highly correlated with the number of voles trapped, although very few cards were chewed in any site. The relative magnitude of GI values for monitoring blocks increased significantly from the binary measure, and GI values were better correlated with the number of voles trapped. For all indices, the variance component due to day was higher than for station.

\section{Discussion}

Monitoring blocks and track plates both show potential as monitoring techniques for meadow voles, although more field testing is needed better to define the relationship between their respective GI values and population size. Monitoring blocks were readily consumed and track plates tracked by meadow voles. They appeared to be sensitive to small changes in population density at low population levels. Monitoring blocks were logistically the easiest indexing method and were durable under all conditions of our study. Track plates were more labour intensive, and often failed owing to rain, or wind blowing vegetation onto the tracking surface. A track plate design such as that developed by Mabee (1998) may result in fewer stations being lost due to these causes but may increase the labour costs. For track plates, we developed a measurement technique that could be considered for indexing a variety of species in different situations. We took a digital photo of each track plate and used graphics software to estimate the number of pixels comprising the tracks. This estimate was highly correlated with the number of tracks, but was less labour intensive and less subjective to acquire, especially for highly tracked plates.

The continuous measurements (amount of monitoring block consumed, number of tracks, or proportion of a plate tracked) associated with monitoring block and track plate methods makes them well suited for calculating an index with variance components (Engeman et al. 1998). With the Gl, the number of stations contributing data each day is allowed to vary. Neither stations nor days are assumed to be independent. Thus, the derivation of the variance estimate does not rely on a potentially unrealistic assumption of inde-

Table 3. Calculated general index (GI) values for continuous and binary measurements of track plate, chew card and monitoring block index methods applied to known populations of meadow voles in outdoor pens

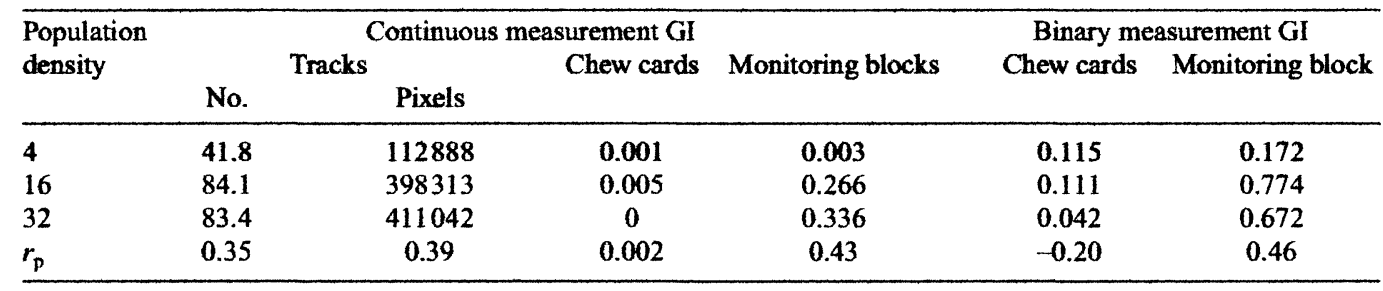


pendence among observations (Engeman et al. 1998). The improved sensitivity of a continuous measurement over a binary measurement for detecting population change was evident in our pen and field tests. In those settings, almost all monitoring block and track plate stations recorded visits regardless of population density. For monitoring blocks, we therefore calculated a binary index based on the proportion of blocks completely consumed. However, blocks were completely consumed on only $13 \%$ of occasions in pen tests and $2 \%$ of occasions in field tests, thus this method was not sufficiently sensitive to the presence of voles under the tested conditions.

General index values calculated for monitoring blocks were highly correlated with the number of meadow voles in our controlled laboratory tests, with the variance component for station (i.e. container of voles) being higher than for day. However, this was not observed in tests with known populations in outdoor pens. Track plate measurements also were poorly correlated with population size. Index values for monitoring blocks and track plates increased for the change in population size from 4 to 16 meadow voles, but results for populations of 16 and 32 meadow voles were similar. It is possible that at the higher population sizes, our index measurements were saturated, but test methods may also be responsible for the poor correlations.

Variance components indicated a high variation in measurements with day. Increasing the number of days for each test may have reduced this variability and provided a better result. We limited the length of tests so that all testing could be completed in a period during which reproduction of the penned voles would not affect known population size. Mortality of voles in the pens may also have been a factor limiting our results in this study. We occasionally found dead meadow voles in the pens and, although we replaced these voles, we were unable to account for any dying below ground. It is also possible that the relatively higher contact rates and competition for resources in the high-populationdensity pens resulted in higher mortality rates for those populations, thus making them more similar to the 16-vole population density.

In our field tests, we also did not observe a strong correlation between GI values and the number of meadow voles trapped, although there was a tendency for the GI to increase from the lowest ( 8 voles trapped) to the highest density (58 voles trapped). We consider that the lack of a significant correlation is more likely due to ineffectiveness of trapping in determining population density rather than failure of the indices. On some sites, we recorded over $80 \%$ trap success on some days (i.e. trap saturation). We also had not completely marked the population by the end of the six-day trapping period. Furthermore, density estimates based on trapping may not provide a reliable estimate of density of microtine populations owing to differences in trappability of juveniles and adults (Boonstra and Krebs 1978; Beacham and Krebs 1980; Redpath et al. 1995).

In contrast to laboratory tests, variance components associated with day were higher than those associated with station in pen and field tests. This may have been due to variation in climatic factors during the testing. Meadow voles are known to vary their activity according to changes in temperature or humidity (Tobin et al. 1992). Increasing the length of the monitoring period might improve the rigour and reliability of these indices, although this would increase the amount of labour required.

Chew cards were well accepted in laboratory tests but not in pen or field tests. In the laboratory tests we often found the chewed remains of cards in vole nesting chambers so we suspect that they were using the cards for nesting material. In natural settings they probably did not need to utilise chew cards owing to the availability of alternative nesting materials. Although chew cards may not be appropriate for indexing meadow voles, they may be useful for other species that are more likely to sample or 'nibble' cards. In the study by Caughley et al. (1998), house mice readily chewed cards with canola oil attractant. An estimate of the percentage of a card chewed was obtained by counting the number of $1-\mathrm{cm}^{2}$ squares remaining. In our study, we developed an easier method of providing a more precise estimate by scanning chewed cards and using graphics software to calculate the number of pixels remaining.

Monitoring blocks and track plates may be potential management tools for other rodent species. In developing these techniques, consideration should be given to the spatial pattern of station placement, the size of grid required to optimise the indices, species specificity, and labour costs to provide a sufficiently sensitive measurement. Logistically,

Table 4. Calculated general index (GI) values for track plate, chew card and monitoring block index methods for four field populations of meadow voles

\begin{tabular}{lcccccc}
\hline Site & $\begin{array}{c}\text { No. of voles } \\
\text { trapped }\end{array}$ & No. of tracks & Binary measure GI & \multicolumn{2}{c}{ Continuous measure GI } \\
& Chew card & Monitoring block & Monitoring block & No. of tracks \\
\hline 2 & 8 & - & 0.025 & 0.825 & 2.68 & - \\
1 & 29 & - & 0.063 & 0.563 & 11.97 & - \\
4 & 47 & 0.625 & 0.109 & 0.438 & 7.94 & 0.36 \\
3 & 58 & 0.875 & 0.109 & 0.672 & 29.96 & 1.29 \\
& $r_{\mathrm{p}}$ & - & 0.98 & -0.57 & 0.79 & - \\
\hline
\end{tabular}


monitoring blocks are easier to apply, are more durable in a range of field situations, and their measurement easier to obtain. The monitoring blocks developed here have been successfully used to monitor other species, including roof rats (Rattus rattus) (D. A. Whisson unpublished data) and Cuban hutia (Capromys pilorides) (R. M. Engeman unpublished data).

\section{Acknowledgments}

This study was funded by the Vertebrate Pest Control Research Advisory Committee of the California Department of Food and Agriculture. We thank Sara Gillespie for her assistance in conducting the tests.

\section{References}

Allen, L., Engeman, M., and Krupa, H. W. (1996). Evaluation of three relative abundance indices for assessing dingo populations. Wildlife Research 23, 197-206.

Beacham, T. D., and Krebs, C. J. (1980). Pitfall versus live-trap enumeration of fluctuating populations of Microtus townsendii. Journal of Mammalogy 61, 486-499.

Boonstra, R., and Krebs, C. J. (1978). Pitfall trapping of Microtus townsendii. Journal of Mammalogy 59, 136-148.

Byers, R. E. (1975). A rapid method for assessing pine vole control in orchards. Horticulture Science 10, 391-392.

Caughley, G. (1977). 'Analysis of Vertebrate Populations.' (John Wiley and Sons: New York.)

Caughley, J., Donkin, C., and Strong, K. (1998). Managing mouse plagues in rural Australia. In 'Proceedings of the Eighteenth Vertebrate Pest Conference'. (Eds R. O. Baker and A. C. Crabb.) pp. 160-165. (University of California: Davis, CA.)

Cruz, F., and Cruz, J. B. (1987). Control of black rats (Rattus rattus) and its effect on nesting dark-rumped petrels in the Galapagos Islands. Vida Silvestre Neotropical 1, 3-13.

Cutler, T. L., and Swann, D. E. (1999). Using remote photography in wildlife ecology: a review. Wildlife Society Bulletin 27, 571-581.

Department of Pesticide Regulation (2002). Section 18 emergency exemption No. 02-18, rodent bait zinc phosphide treated grain (2.0\%) (EPA Reg. No. 10965-50015)/Alfalfa/California voles (Microtus californicus) and montane vole (Microtus montanus). (Department of Pesticide Regulation: Sacramento, CA.)

Drennan, J. E., Beier, P., and Dodd, N. L. (1998). Use of track stations to index abundance of sciurids. Journal of Mammology 79, 352-359.

Engeman, R. M. and Whisson, D. A. (2003). A visual method for indexing muskrat populations. International Biodeterioration \& Biodegradation 52, 101-106. doi:10.1016/S0964-8305(03)00031-3

Engeman, R. M., and Witmer, G. W. (2000). IPM strategies: indexing difficult to monitor populations of pest species. In 'Proceedings of the Nineteenth Vertebrate Pest Conference'. (Eds T. P. Salmon and A. C. Crabb.) pp. 183-189. (University of California: Davis, CA.)
Engeman, R. M., Allen, L., and Zerbe, G. O. (1998). Variance estimate for the Allen activity index. Wildlife Research 25, 643-648. doi:10.1071/WR97073

Hayes, J. P., and Cullinan, V. I. (1984). An evaluation of the relationship between the apple index and vole density. In 'Proceedings of the Eighth Eastern Pine and Meadow Vole Symposium'. (Ed. R. E. Byers.) pp. 31-43.

Johnson, M. L., and Johnson, S. (1982). Voles. In 'Wild Mammals of North America. Biology, Management and Economics'. (Eds J. Chapman and G. Geldhamer.) pp 347-348. (The Johns Hopkins University Press: Baltimore, MD.)

Mabee, T. J. (1998). A weather-resistant tracking tube for small mammals. Wildlife Society Bulletin 26, 571-574.

McLean, R. A., Sanders, W. L., and Stroup, W. W. (1991). A unified approach to mixed linear models. American Statistician 45, 54-64.

O'Brien, J. M. (1994). Voles. In 'Prevention and Control of Wildlife Damage'. (Eds S. E. Hyngstrom, R. M. Timm and G. E. Larson.) pp. B177-181. (University of Nebraska Cooperative Extension, US Department of Agriculture, Animal and Plant Health Inspection Service, Animal Damage Control, and Great Plains Agricultural Council, Wildlife Committee: Lincoln, NE.)

Redpath, C. J., Thirgood, S. J., and Redpath, S. M. (1995). Evaluation of methods to estimate field vole Microtus agrestis abundance in upland habitats. Journal of Zoology 237, 49-55.

Salmon, T. P., Dochterman, N. A., and Whisson, D. A. (2002). Rodent bait quality - ingredients and manufacturing processes. Final report to the California Department of Food and Agriculture on completion of project 99-0660. California Department of Food and Agriculture, Integrated Pest Control Branch, Sacramento, CA50.

SAS Institute (1996). 'SAS/STAT User's Guide.' (SAS Institute: Carey, NC.)

Searle, S. R., Casella, G., and McCulloch, C. E. (1992). 'Variance Components.' (Wiley \& Sons: New York.)

Taylor, R. H., and Thomas, B. W. (1993). Rats eradicated from rugged Breaksea Island (170 ha), Fiordland, New Zealand. Biological Conservation 65, 191-198. doi:10.1016/0006-3207(93)90052-3

Tobin, M. E., Richmond, M. E., and Engeman, R. M. (1992). Comparison of methods for detecting voles under apple trees. In 'Proceedings of the Fifth Eastern Wildlife Damage Control Conference'. (Eds P. D. Curtis, M. J. Fargione and J. E. Caslick.) pp. 201-204. (Cornell Cooperative Extension, Department of Natural Resources.)

Wolfinger, R. D., Tobias, R., and Sall, J. (1991). Mixed models: a future direction. In '16th SAS Users Group Conference'. (Ed. M. Rosenburg.) pp. 1380-1388. (SAS Institute: Carey, NC.)

Manuscript received 23 December 2003, accepted 24 February 2005 